\title{
UTILIZAÇÃO DA MICROSCOPIA ELETRÔNICA DE VARREDURA COMO FERRAMENTA DE AVALIAÇÃO DA ESTRUTURA DO TECIDO DE ABACATE 'QUINTAL' APÓS DANOS MECÂNICOS ${ }^{1}$
}

\author{
JULIANA SANCHES ${ }^{2}$, JOSÉ FERNANDO DURIGAN ${ }^{3}$, JAIME MAIA DOS SANTOS ${ }^{4}$
}

RESUMO - Avaliaram-se os efeitos de injúrias mecânicas, por impacto, compressão e corte nas estruturas celulares de abacates 'Quintal'. Na injúria por impacto, eles foram deixados cair, em queda livre, de uma altura de 2,00 m, sobre os lados opostos, de sua região equatorial; na compressão, foram colocados sob um peso de 117,6 N, por 24 horas, o que provocou duas lesões opostas, no sentido longitudinal; e os cortes foram aplicados em número de quatro, longitudinalmente, com $40 \mathrm{~mm}$ de comprimento e $4 \mathrm{~mm}$ de profundidade, nos lados opostos dos frutos. Após 5 dias de armazenamento, sob condições de ambiente $\left(25^{\circ} \mathrm{C}\right.$ e $60 \%$ UR), procedeuse à verificação das estruturas celulares através de microscopia eletrônica de varredura. A microscopia eletrônica de varredura indicou que os abacates injuriados por compressão e impacto, embora sem lesões aparentemente visíveis, apresentavam desordem celular em suas estruturas.

Termos para indexação: compressão, corte, impacto, microscopia eletrônica de varredura, Persea americana

\section{USE OF SCANNING ELECTRONIC MICROSCOPY AS TOOL OF THE TISSUE STRUCTURE EVALUATION OF 'QUINTAL’AVOCADO TISSUE STRUCTURE AFTER MECHANICAL INJURIES}

\begin{abstract}
This work aimed to evaluate the effects of mechanical injuries, by impact, compression and cut in the cellular structures of 'Quintal' avocados. In the injury by impact, they were submitted, by free fall, to a height of $2.00 \mathrm{~m}$, in opposed sides of their equatorial area; in the compression, they were submitted by a weight of $117.6 \mathrm{~N}$ for 24 hours, and it provoked two opposite lesions in the longitudinal area; and the cuts were longitudinally applied at number of four, with $40 \mathrm{~mm}$ of length and $4 \mathrm{~mm}$ of depth in the opposed sides of the fruits. After 5 days of storage, under the laboratory conditions $\left(25^{\circ} \mathrm{C}\right.$ and $\left.60 \% \mathrm{RH}\right)$, the verification of the cellular structures was proceeded through scanning electron microscopy, which indicated that the injuried avocados by compression and impact, although without apparently visible lesions, presented cellular disorder in their structures.
\end{abstract}

Index terms: compression, cut, impact, scanning electronic microscopy, Persea americana

\section{INTRODUÇÃO}

O Brasil é o quarto, dentre os maiores produtores mundiais de abacates. A produção brasileira, em 2004, foi de 173 mil toneladas (FAO, 2004) e está distribuída principalmente nas regiões Sudeste, Nordeste e Sul, sendo o Estado de São Paulo o maior produtor, com produção estimada, em 2003, de 92 mil toneladas (53\% do total nacional) (IBGE, 2004).

Atualmente, a produção de frutas com alta qualidade, objetivando a comercialização das mesmas como produtos frescos, em mercados cada vez mais exigentes, tem sido a tônica da fruticultura brasileira (SOUZA, 2001). Por outro lado, ainda se perde muito da produção frutícola durante a fase pós-colheita, em função do desconhecimento das técnicas de conservação.

As lesões mecânicas, durante o manejo na colheita e póscolheita, são responsáveis por perdas significativas durante a distribuição e a comercialização. Elas afetam diretamente a aparência externa, que é um dos mais importantes atributos de qualidade das frutas, e é o principal fator de rejeição pelo consumidor.
As injúrias mecânicas são definidas como deformações plásticas, rupturas superficiais e destruição dos tecidos vegetais, provocadas por forças externas. Adicionalmente, levam a modificações físicas (danos físicos) e/ou alterações fisiológicas, químicas e bioquímicas que modificam a cor, o aroma, o sabor e a textura dos vegetais (MOHSENIN, 1986). Dentre as injúrias mais comuns, destacam-se as causadas por impacto, compressão e corte.

A injúria por impacto é geralmente causada pela colisão do fruto contra superfícies sólidas ou contra outros frutos, durante as etapas de colheita, manuseio e transporte. Ela pode causar danos externos, que são facilmente visualizados na superfície, com a ruptura ou não da epiderme e a formação de lesões aquosas translúcidas e amolecimento. Além disso, essas injúrias são responsáveis pela retirada da primeira linha de defesa do fruto colhido, permitindo a entrada de patógenos. A ocorrência de impactos pode não causar sintomatologia externa prontamente observável, mas seu efeito acaba repercutindo mais tarde, dada a produção de injúrias internas (QUINTANA \& PAULL, 1993; MORETTI, 1998).

1 (Trabalho 035-2006) Recebido:em 22-03-2006 . Aceito para publicação em 08-01-2007. Parte da tese de doutorado do primeiro autor, em Agronomia, Área de Concentração: Produção Vegetal, na UNESP/ FCAV, Jaboticabal - SP. Processo FAPESP n 02/08828-3

${ }^{2}$ Enga Agra , Dra., Pesquisadora Científica do Instituto Agronômico / Centro de Engenharia e Automação. Rod. D. Gabriel P. B. Couto, km 65 CP 26 CEP: 13.201-970, Jundiaí, SP, e-mail: jsanches@iac.sp.gov.br

${ }^{3}$ Prof. Titular, Departamento de Tecnologia, Faculdade de Ciências Agrárias e Veterinárias, UNESP, Campus de Jaboticabal, SP, e-mail: jfduri@fcav.unesp.br ${ }^{4}$ Prof. Dr., Departamento de Fitossanidade, Faculdade de Ciências Agrárias e Veterinárias, UNESP, Campus de Jaboticabal, SP, e-mail: jmsantos@fcav.unesp.br 
A injúria mecânica por compressão é causada pela imposição de uma pressão variável contra a superfície externa do fruto, quer seja por um fruto adjacente, quer pela própria parede da embalagem em que está acondicionado o produto. Neste caso, a deformação causada pode ser irreversível e a obstrução à difusão de $\mathrm{O}_{2}$ foi sugerida como uma das causas dos sintomas de compressão (CALBO et al., 1995).

A injúria por corte é geralmente atribuída a uma forte colisão do fruto contra uma superfície irregular, ou pela imposição de uma superfície cortante e com pressão sobre o fruto, como as arestas de uma embalagem de colheita ou objetos cortantes. Independentemente do caso, o resultado deverá ser o rompimento e a perda da integridade celular na região do corte (MOHSENIN, 1986; WILEY, 1997).

A suscetibilidade ao dano mecânico é influenciada por vários fatores, como espécie, cultivar, grau de hidratação celular, estádio de maturação, tamanho, peso, características epidérmicas e condições ambientais (WADE \& BAIN, 1980; KAYS, 1991).

Injúrias mecânicas podem causar alterações na síntese de pigmentos de alguns frutos, tornando-os inviáveis à comercialização. Ao submeterem maçãs 'Granny Smith' à injúria por impacto, SAMIM \& BANKS (1993) observaram mudanças na coloração, ou seja, um rápido escurecimento e a formação de compostos de coloração marrom, provavelmente devido à ação da enzima polifenoloxidase, nos locais injuriados, algumas horas após a ocorrência da injúria.

Em adição aos típicos sintomas externos e internos, as injúrias mecânicas em frutas são geralmente acompanhadas por elevado número de respostas fisiológicas. Quando tecidos vegetais são lesionados, ocorre elevação na atividade respiratória e na produção de etileno, algumas vezes dentro de poucos minutos, mas usualmente dentro de uma hora (ABELES et al., 1992; BRECHT, 1995). O etileno acelera a deterioração e a senescência dos tecidos vegetais e promove o amadurecimento de frutas climatéricas, levando a diferenças na idade fisiológica entre os tecidos intactos e os feridos (WATADA et al., 1990).

Vários autores constataram que frutos submetidos a injúrias mecânicas apresentaram alterações na evolução do $\mathrm{CO}_{2}$ e do etileno. BURTON \& SCHULTE-PASON (1987) constataram que mirtilos submetidos a injúrias por impacto aumentaram, significativamente, a evolução de $\mathrm{CO}_{2}$, com o aumento do número de impactos. No mesmo experimento, estes autores evidenciaram uma correlação entre o número de impactos e o subseqüente desenvolvimento de podridões. Injúrias por impacto, vibrações e compressão também foram responsáveis por aumentos na atividade respiratória de tangerinas 'Satsuma' (IWAMOTO et al., 1984; YUTAKA et al., 1984), cerejas (WADE \& BAIN, 1980; MASSEY et al., 1982), laranjas (PARKER et al., 1984) e goiabas (MATTIUZ, 2002).

Ao estudar a relação entre as injúrias mecânicas e as características organolépticas, MORETTI \& SARGENT (2000) observaram que as injúrias se mostraram capazes de alterar o aroma, o sabor e a textura de tomates.

CHUMA et al. (1984) verificaram que morangos submetidos a injúrias por impacto, durante o transporte, apresentaram maior perda de água do que os frutos nãotransportados.
No caso do abacate, os danos externos não levam a efeito imediato e somente quando a fruta amadurece, a polpa se apresenta, parcial ou totalmente, escura. A queda durante a colheita, a colocação das frutas nas embalagens e o modo como são transportadas são algumas das operações que lhes têm causado danos mecânicos, comprometendo sua qualidade (BLEINROTH \& CASTRO, 1992).

A utilização do microscópio eletrônico e a melhoria das técnicas de preparação das amostras ampliaram, sobremaneira, a nossa capacidade de observação da ultra-estrutura celular. Muitas concepções sobre a morfologia de certos organismos sobre a organização de tecidos e funções celulares foram radicalmente alteradas. Nenhuma outra ferramenta de pesquisa experimentou tão rápido avanço, em toda a história da ciência, quanto os microscópios eletrônicos de transmissão e de varredura (SANTOS, 1996).

A microscopia eletrônica de varredura tem sido utilizada para diversos fins, como para fiscalizar a qualidade do café torrado e moído, fraudado por cereais (AMBONI et al.,1999); para observar a camada de cera de maçãs refrigeradas (CASTRO et al., 2002) e para avaliar danos mecânicos em melões, causados pelo congelamento (RESENDE \& CAL-VIDAL, 2002).

Este trabalho objetivou avaliar a estrutura do tecido de abacates 'Quintal', através de microscópio eletrônico de varredura, submetidos às injúrias mecânicas: impacto, compressão e corte.

\section{MATERIAL E MÉTODOS}

Frutos de abacateiro da cultivar Quintal foram utilizados para este experimento. O período de colheita desse abacate é de março a junho, é do tipo floral B, e o formato dos frutos é oblongo, com pescoço e peso variando de $400 \mathrm{~g}$ a $600 \mathrm{~g}$ (DONADIO, 1995).

Os frutos foram cuidadosamente colhidos com coloração verde-opaca e mostrando facilidade para a separação da planta (BLEINROTH, 1995), em propriedade agrícola do município de Jardinópolis - SP. Logo após a colheita, esses frutos foram cuidadosamente transportados para o Laboratório de Tecnologia dos Produtos Agrícolas da FCAV/UNESP - Jaboticabal-SP. Após imersão em água fria $\left(15^{\circ} \mathrm{C}\right)$ clorada $\left(150 \mathrm{mg}\right.$ de cloro. $\left.\mathrm{L}^{-1}\right)$, por cinco minutos, e repouso por 1 hora, os frutos foram submetidos às injúrias mecânicas.

Além dos frutos que não sofreram qualquer tipo de lesão (Testemunha), houve os que receberam as injúrias, num total de 3 repetições por tratamento. Para o Impacto, eles foram deixados cair, em queda livre, de uma altura de $2,00 \mathrm{~m}$. Cada fruto sofreu dois impactos, em lados opostos, na sua região equatorial. Para a injúria por Compressão, eles foram colocados sob uma massa de $12 \mathrm{~kg}$, por 24 horas, provocando 2 lesões opostas, no sentido longitudinal dos frutos. O lesionamento por cortes foi conseguido aplicando-se quatro cortes longitudinais, com $40 \mathrm{~mm}$ de comprimento e $4 \mathrm{~mm}$ de profundidade, nos lados opostos dos frutos. As áreas lesionadas foram demarcadas, e os frutos armazenados sob condição de ambiente $\left(25 \pm 1^{\circ} \mathrm{C}\right.$ e $60 \pm 6 \%$ UR).

Após cinco dias de armazenamento, quando os frutos já se encontravam totalmente maduros, mas com textura ainda firme,

Rev. Bras. Frutic., Jaboticabal - SP, v. 29, n. 1, p. 057-060, Abril 2007 
procedeu-se à análise das estruturas dos tecidos injuriados mecanicamente, através de microscopia eletrônica de varredura. As amostras de polpa, medindo $1 \times 1 \times 0,5 \mathrm{~cm}$ (comprimento $\mathrm{x}$ largura $\mathrm{x}$ altura), foram retiradas do local da injúria, usando-se lâmina de bisturi, e foram fixadas, imediatamente, em glutaraldeído a 3\%, em tampão de fosfato de potássio a $0,05 \mathrm{M} \mathrm{e} \mathrm{pH} \mathrm{7,4,} \mathrm{por} 72$ h. A seguir, foram lavadas por seis vezes consecutivas com a solução tampão pura, em um intervalo de 15 minutos e pós-fixadas em tetróxido de ósmio a 2\%, no mesmo tampão, por cerca de $12 \mathrm{~h}$. Posterirmente, foram novamente lavadas com a solução tampão, desidratadas em uma série gradual de álcool etílico (30; 50; 70; 80; 90; 95; 100; 100 e 100\%), durante 20 minutos em cada solução, secas em secador de ponto crítico, utilizando-se de $\mathrm{CO}_{2}$, montadas, metalizadas com cerca de $35 \mathrm{~nm}$ de ouro-paládio, observadas e eletromicrografadas em microscópio eletrônico de varredura JEOL JSM 5410, operado em $15 \mathrm{kV}$ (SANTOS \& MAIA, 1997).

\section{RESULTADOS E DISCUSSÃO}

Na Figura 1, é apresentada a estrutura do tecido do abacate 'Quintal', quando livre de injúrias mecânicas e depois que o mesmo foi injuriado. Na Figura 1A, observa-se que, em sua estrutura, há células oleaginosas, facilmente identificáveis.

Os frutos que sofreram Compressão não apresentaram sintomas externos prontamente visíveis, ou seja, o pericarpo dos frutos mostrou-se intacto após a injúria, mas quando se fez a observação de suas estruturas em microscópio eletrônico de varredura, observou-se desarranjo, como é mostrado na Figura 1 B. Esses desarranjos, provavelmente, foram causados pelo colapso dos carboidratos após a injúria (CHINACHOTI \& STEINBERG, 1984), bem como pelo rompimento das células oleaginosas.
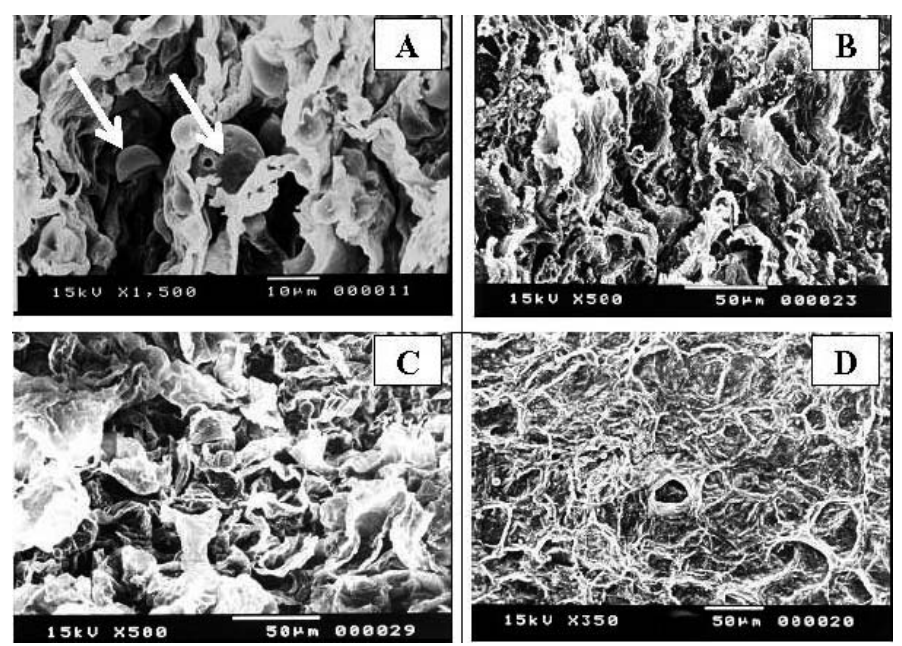

FIGURA 1 - Eletromicrografias de varredura da estrutura do tecido de abacates 'Quintal' submetidos a diferentes injurias, após cinco dias de armazenamento sob condições de ambiente $\left(25^{\circ} \mathrm{Ce} 60 \%\right.$ UR). Livre de injúrias (A); Compressão (B); Impacto (C), e Corte (D). Setas indicam células oleaginosas.
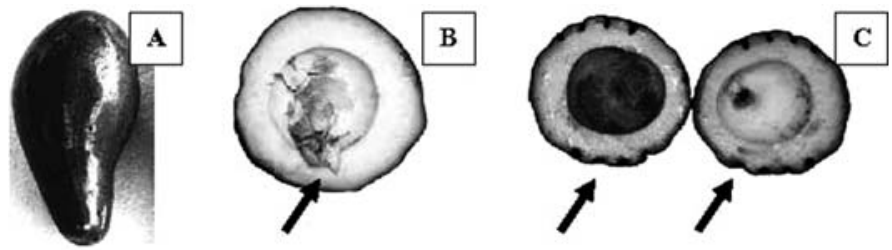

FIGURA 2 - Aparência de abacates 'Quintal' submetidos a injúria por impacto e corte, após cinco dias de armazenamento sob condições de ambiente $\left(25^{\circ} \mathrm{C}\right.$ e $60 \%$ UR). Aparência externa de abacate injuriado por impacto (A); aparência interna de abacate injuriado por impacto (B); aparência interna de abacate injuriado por corte (C).

$\mathrm{Na}$ injúria por Impacto, os abacates também não apresentaram sintomas externos (Figura $2 \mathrm{~A}$ ), mas, internamente, apresentaram fissuras na polpa, próximas ao caroço (Figura $2 \mathrm{~B}$ ). À medida que os frutos foram amadurecendo, essas fissuras aumentaram, mas, ao mesmo tempo, o caroço produziu tecido para preenchê-las e inibir seu avanço pela polpa. Na Figura $1 \mathrm{C}$, é mostrada a estrutura microscópica do tecido que preencheu essa fissura, em cinco dias, e pode-se observar que o mesmo apresenta estrutura desordenada, como o apresentado pelos frutos injuriados por compressão.

Os cortes apresentaram-se como traços escurecidos na polpa e, após cinco dias de armazenamento, essa área já estava totalmente cicatrizada (Figura $2 \mathrm{C}$ ), devido ao espessamento dos tecidos nessa região (Figura 1D).

\section{CONCLUSÃO}

A microscopia eletrônica de varredura mostrou que os tecidos da polpa de abacates 'Quintal', quando injuriados mecanicamente, apresentaram desordem em suas estruturas e que eles são protegidos por diferentes processos de cicatrização.

\section{AGRADECIMENTOS}

Os autores agradecem à UNESP/FCAV e à FAPESP (Proc. $\left.\mathrm{n}^{\circ} 02 / 08828-3\right)$.

\section{REFERÊNCIAS}

ABELES, F.B.; MORGAN, P.W.; SALTWEIT, M.E. Ethylene in plant biology. $2^{\text {nd }}$ ed. San Diego: Academic Press, 1992.

AMBONI, R. D. de M. C.; FRANCISCO, A. de; TEIXEIRA, E. Utilização de microscopia eletrônica de varredura para detecção de fraudes em café torrado e moído. Ciência e Tecnologia de Alimentos, Campinas, v. 19, n. 3. p. 331-313, 1999.

BLEINROTH, E.W. Colheita e tratamentos. In: GAYET, J.P. et al. (Ed.). Abacate para exportação: procedimentos de colheita $\mathrm{e}$ pós-colheita. Brasília: Embrapa-SPI, 1995. p. 10-23.

BLEINROTH, E.W.; CASTRO, J.V. de. Matéria-prima. In: ITAL. Abacate: cultura, matéria-prima, processamento e aspectos econômicos. 2. ed. Campinas: ITAL, 1992. p. 58-148. 
BRECHT, J.K. Physiology of lightly processed fruits and vegetables. HortScience, Alexandria, v. 30, n. 1, p. 18-22, 1995.

BURTON, C.L.; SCHULTE-PASON, N.L. Carbon dioxide as an indicator of fruit impact damage. HortScience, Alexandria, v. 22, n. 2, p. 281-282, 1987.

CALBO, A.G.; NERY, A.A.; HERMANN, P.S.P. Intercellular deformation in compressed organs. Annals of Botany, London, v. 76, p. 365-370, 1995.

CASTRO, L. A. S. de; SANHUEZA, R. M. V.; CANTILLANO, R. F. F.; ROCHA, N. E. M. Metodologia para observação da camada de cera em maçãs, utilizando microscopia eletrônica de varredura. Revista Brasileira de Fruticultura, Jaboticabal, v. 24, n. 3. p. 774-775, 2002.

CHINACHOTI, P.; STEINBERG, M.P. Interaction of sucrose with starch during dehidration as shown by water sorption. Journal of Food Science, Chicago, v. 49, p. 1604-1608, 1984.

CHUMA, Y.; MURATA, S.; IWAMOTO, M.; NISHIHARA, A.; HORI, Y. Donner strawberry transportation in refrigerated truck for 700 kilometers. Annals of the Agricultural Engineering Society, Washington, v. 45, n. 2, p. 292-297, 1984.

DONADIO, L. C. Abacate para exportação: aspectos técnicos de produção. Brasília, DF: DENACOOP. 109p. 1995. (Série publicações técnicas, DENACOOP/ FRUPEX, 2).

FOOD AGRICULTURAL ORGANIZATION - FAO (2004). Statistical database. Disponível em: 〈www.apps.fao.org>. Acesso em: 12 jun. 2005.

INSTITUTO BRASILEIRO DE GEOGRAFIAEESTATÍSTICAIBGE. Produção Agrícola Municipal. 2004. Disponível em: <www.sidra.ibge.gov.br>. Acesso em: 13 jun. 2005.

IWAMOTO, M.; HAYAKAWA, A.; KAWANO, S.; MANAGO, $M$. Effect of dropping practice in packing house lines on the quality of Satsuma mandarin. Annals of the Engineering Society, Washington, v. 45, n. 4, p. 539-544, 1984.

KAYS, J.S. Postharvest physiology of perishable plant products. New York: Van Nostrand Reinhold, 1991.453p.

MASSEY, L.M.; CHASE, B.R.; STARR, M.S. Effect of rough handling on $\mathrm{CO}_{2}$ evolution from 'Howes' cranberries. HortScience, Alexandria, v. 17, p. 57-58, 1982.

MATTIUZ, B.H. Injúrias mecânicas e processamento mínimo de goiabas: fisiologia e qualidade pós-colheita. 2002. $120 \mathrm{f}$. Tese (Doutorado em Produção Vegetal) - Faculdade de Ciências Agrárias e Veterinárias - Universidade Estadual Paulista, Jaboticabal, 2002.

MOHSENIN, N.N. Physical properties of plant and animal materials: structure, physical characteristics and mechanical properties. New York: Gordon and Breach, 2 nd ed., 1986, 891p.

MORETTI, C.L. Injúrias internas de impacto em frutos de tomate: fisiologia e conservação pós-colheita. 1998. 132f. Tese (Doutorado em Produção Vegetal) - Universidade Federal de Viçosa, Viçosa, 1998.

MORETTI, C.L.; SARGENT, S.A. Alteração de sabor e aroma em tomates causada por impacto. Scientia Agrícola, Piracicaba, v. 57, n.3, p. 385-388, 2000.
PARKER, M.L.; WARDOWSKI, W.F.; DEWEY, D.H. A damage test for oranges in a commercial packing house line. Proceedings of the Florida State Horticultural Society, Winter Haven, v. 97, p. 136-137. 1984.

QUINTANA, M.E.G.; PAULL, R.E. Mechanical injury during postharvest handling of 'Solo' papaya fruit. Journal of the American Society for Horticultural Science, Alexandria, v. 118, n. 5, p. 618-622. 1993.

RESENDE, J. V.; CAL-VIDAL, J. Frutos de melão submetidos a pré-tratamentos com hidrocolóides: efeitos do processo de congelamento sobre a microestrutura celular. Ciência e Tecnologia de Alimentos, Campinas, v. 22, n. 3. p. 295-304, 2002.

SAMIM, W.; BANKS, N.H. Colour changes in bruised apple fruit tissue. New Zealand Journal of Crop and Horticultural Science, Wellington, v. 21, n. 4, p. 367-372, 1993.

SANTOS, J. M. dos. Microscopia eletrônica de varredura aplicada às ciências biológicas. Jaboticabal: FUNEP, 1996. 56p. Apostila

SANTOS, J. M.; MAIA, A. S. dos. A SEM technique for preparing biological control agents of nematodes in action. Acta Microscopica, Rio de Janeiro, v. 6, Suppl. B, p. 550-551, 1997.

SOUZA, R.A.M. de. Mercado para produtos minimamente processados. Informações Econômicas, São Paulo, v. 31, n. 3, p. 7-18, 2001.

WADE, N.L.; BAIN, J.M. Physiological and anatomical studies of surface pitting of sweet cherry fruit in relation to bruising, chemical treatments and storage conditions. Journal of Horticultural Science, Ashford, v. 55, n. 4, p. 375-384. 1980.

WATADA, A.; ABE, K.; YAMAUCHI, N. Physiological activities of partially processed fruits and vegetables. Food Technology, Chicago, v. 20, p. 116-122, 1990.

WILEY, R.C. Frutas y hortalizas mínimamente procesadas y refrigeradas. Zaragoza: Editorial Acribia, 1997, 363p.

YUTAKA, C.; HIROMI, I.; TAKAHISA, M. Bruise and respiration characteristics of citrus 'Unshiu' as related to material handling and in-transit injury. Annals of the Engineering Society, Washington, v. 45, n. 1, p. 104-108, 1984.

Rev. Bras. Frutic., Jaboticabal - SP, v. 29, n. 1, p. 057-060, Abril 2007 